\title{
Dynamic structural health monitoring of a model wind turbine tower using distributed acoustic sensing (DAS)
}

\author{
Peter G. Hubbard ${ }^{1}$ (D) . James $\mathrm{Xu}^{1}$ - Shenghan Zhang ${ }^{1} \cdot$ Matthew Dejong $^{1} \cdot$ Linqing Luo $^{1} \cdot$ Kenichi Soga $^{1} \cdot$ Carlo Papa $^{2}$. \\ Christian Zulberti ${ }^{2} \cdot$ Demetrio Malara $^{3} \cdot$ Fabio Fugazzotto $^{3} \cdot$ Francisco Garcia Lopez $^{3} \cdot$ Chris Minto $^{4}$
}

Received: 15 October 2020 / Revised: 3 April 2021 / Accepted: 13 April 2021 / Published online: 5 May 2021

(c) The Author(s) 2021

\begin{abstract}
Maintenance of wind turbine towers is currently a manual process that requires visual inspection and bolt tightening yearly. This process is costly to energy companies and its necessity is not well-defined. In this study, two Rayleigh-based distributed fiber optic sensing technologies are evaluated and compared for their ability to monitor the dynamic structural behavior of a model wind turbine tower subject to free and forced vibration. They are further tested for their ability to detect structural phenomena associated with loose bolts and material damage within the tower. The two technologies examined are optical frequency domain reflectometry (OFDR) and phase-based optical time domain reflectometry ( $\phi$-OTDR), which is a technology used in distributed acoustic sensing (DAS). OFDR is a tested and proven strain measurement technology commonly used for structural health monitoring but can only make strain measurements over short distances (10 s of meters). OFDR was used to validate the measurements made with $\phi$-OTDR which can measure over much longer distances (several kilometers). Due to its sensing distance capability, $\phi$-OTDR is a promising technology for monitoring many wind turbines networked together with a single fiber optic cable. This study presents a first-of-its-kind use of $\phi$-OTDR for structural health monitoring to demonstrate its capabilities.
\end{abstract}

Keywords Distributed acoustic sensing · Distributed fiber optic sensing · Dynamic strain sensing · Wind turbine · Structural health monitoring $\cdot$ Loose bolt detection

\section{Introduction}

Wind energy generation capacity worldwide increased from $24 \mathrm{GW}$ in 2001 to $568 \mathrm{GW}$ by the end of 2018 [1]. Over that same timeframe, wind power was responsible for $15 \%$ of the increase in electricity generating capability globally $[2,3]$. Simultaneously, O\&M costs for land-based wind turbines fell by nearly 50\% [4]. Procedure improvement and technology advancements have been the main cause for these cost decreases, and in turn have helped the growth of investments in wind energy. Trends suggest that this will continue,

Peter G. Hubbard

phubbard@berkeley.edu

1 Department of Civil and Environmental Engineering, University of California, Berkeley, CA, USA

2 Enel Foundation, Rome, Italy

3 Enel Green Power, Rome, Italy

4 Optasense Ltd, Farnborough, UK with Denmark's Energinet projecting that fixed O\&M costs for onshore wind power will fall $17 \%$ between 2020 and 2040 [5]. Currently, manual bolt tensioning is conducted for all bolts yearly on Enel Group's wind turbine towers. This effort accounts for up to $10 \%$ of the operational expenditure. Decreasing the necessity for manual bolt inspection and tightening by assessing the structural health remotely is desired to lower this cost. The purpose of this study is to test a novel structural health monitoring technique to detect loose bolts and tower damage. The technique being evaluated is based on distributed acoustic sensing (DAS), a method commonly used to monitor long linear assets such as pipelines for acoustic signals caused by leaks or third party intrusion. The acoustic signals are proportional to dynamic strain in the optical fiber sensing element, making structural health monitoring (SHM) a possibility [6]. The driving factor behind testing this technology for SHM is its large maximum sensing distance of $10 \mathrm{~km}$. This may be a solution for monitoring several wind turbines networked together along a single continuous fiber optic cable. 


\subsection{Structural health monitoring of wind turbine towers}

Structural health monitoring for wind turbine tower structures has heavily focused on modal analysis, usually from accelerometer data and using widely varying data analytic methods [7-10]. These methods quantify the dynamic structural properties of the towers based on their observed vibrational characteristics. Many studies have been conducted on detecting damage based upon changes in these dynamic properties, which have been met with generally good results [9-12]. Vibration-based techniques evaluate the global structural behavior and can identify changes that indicate damage. They cannot localize where the damage occurs or make observations about the cause, be it bolt loosening or something else. In fact, studies have been done to evaluate modal analysis for its ability to detect loose bolts specifically $[13,14]$. These studies found that the first-mode fundamental frequency of large turbine towers can be minimally affected by bolt loosening, making detection difficult. When detection succeeds, localization is still difficult. Practically, there is little value in detecting loose bolts in a turbine tower structure if localization is not possible. This is because the entire tower where a loose bolt is detected would need to be manually inspected. If, however, both detection and localization are possible, engineers would be able to make informed decisions about the importance of addressing bolt tightness on a tower by tower, joint by joint basis. This would provide significant value by reducing $\mathrm{O} \& \mathrm{M}$ costs because currently each bolt is manually tightened yearly regardless of if it is loose or not.

More recently, dynamic measurements of material strain have been made to quantify the behavior of towers and detect damage. Changes in both the strain fields and dynamic properties have been examined for their damage identification abilities. The main challenge of the methods that have been investigated is that material strain has been measured at discrete locations, again making localization of damage difficult. This has required researchers to make assumptions about the strain fields and use indirect methods for quantifying if damage has occurred between two points. These measurement technologies have included foil strain gauges and Fiber Bragg Grating (FBG) fiber optic sensing $[15,16]$. FBG-based fiber optic sensing is considered quasicontinuous because it makes measurements at discrete locations along an optical fiber. FBGs are periodic changes in the refractive index of an optical fiber spanning about $50 \mathrm{~mm}$ of the optical fiber that are created during the manufacturing process [17]. Strain is measured at the specific location of the FBG.

This study investigates a completely different method for monitoring wind turbine tower structures. Distributed fiber optic sensing (DFOS) uses the distributed length of a sensing fiber to make measurements that describe the entire length of the sensor [18]. With proper data analytics, the behavior of the entire sensing length can be resolved without leaving spatial gaps along a sensing line. In the case of wind turbine towers, the geometry leads perfectly to this type of sensing. A tower can be measured with vertical sensing lines that are directly adhered to the extreme axis extents of the tower. The distributed strain measurements can be made dynamically with certain DFOS technologies, and is referred to here as dynamic, distributed fiber optic sensing (DDFOS) [19]. When distributed strain measurements are made at sufficiently high rates that the natural vibrational frequencies of the structure can be measured without time-aliasing, a comprehensive observation set of the structure can be made. These observations fully resolve the 3-D dynamic structural behavior including vibrational modes and magnitudes, while giving the added benefit of being able to localize strain concentrations caused by damage or bolt loosening over the tower length.

\subsection{DFOS applications in civil infrastructure}

DFOS techniques have been widely used for civil infrastructure monitoring applications including piles, retaining walls, bridges, buildings, dams, tunnels, and pipelines [20, 21]. Techniques vary based on light scattering phenomena and analysis method. Scattering phenomena include Rayleigh, Brillouin, and Raman scattering. Rayleigh and Brillouin scattering are used in distributed strain and temperature sensing (DSTS), while Raman scattering is only used for distributed temperature sensing (DTS) [21]. For most civil infrastructure monitoring applications, it is adequate to take strain measurements at sparse time intervals. Common time sampling intervals are anywhere from several hours to days or even weeks between measurements [22-24]. In specific scenarios, however, data acquisition is desired at much higher rates. An example of this is the detection of a transient crack that only opens briefly during dynamic loading. The strain across the crack would need to be measured as a sufficiently high rate to both measure the strain and describe the behavior in time.

DDFOS techniques have been used to monitor transportation infrastructure. These deployments have included technologies based on both Brillouin and Rayleigh scattering. Brillouin-based DDFOS methods have been validated in a laboratory setting to detect damage in steel bridge structures [25]. This study presented a configuration where data were acquired at $13 \mathrm{~Hz}$ and reported a sensitivity of $40 \mu \varepsilon$. More recently, Brillouin-based DDFOS was deployed in the field on both a precast post-tensioned concrete box girder bridge and a three-span continuous steel girder bridge [26]. In this study, the measurements 
were used to compute damage indices. It was determined that the system was efficient in detecting the majority of anomalies in the bridges.

Rayleigh-based DDFOS has been used to monitor reinforced concrete beams in a laboratory setting [27] and railways in both the laboratory and field [28]. The Rayleighbased DDFOS methods reported in the civil SHM literature make use of commercial optical frequency-domain reflectometry (OFDR) systems. Such systems have high accuracy and spatial resolution, but limited sensing distance. The study conducted by Broth and Hoult, 2020 [27] on the dynamic behavior of reinforced concrete beams used a system (Luna Innovations ODiSI-B) with an accuracy, spatial resolution, and maximum sensing distances of $\pm 25 \mu \varepsilon$, $5.2 \mathrm{~mm}$ and $5 \mathrm{~m}$, respectively [29]. This study uses a similar system to [27] as a verification tool for a new, much longer range DDFOS system. The principles of both Rayleighbased DDFOS systems are introduced in the next section.

\subsection{Rayleigh-based DDFOS technologies}

In this study, two DDFOS technologies were deployed to monitor the dynamic structural behavior of a model wind turbine tower. The technologies used are optical frequency domain reflectometry (OFDR) and phase-based optical time domain reflectometry ( $\phi$-OTDR). $\phi$-OTDR is the measurement technique used in high-end distributed acoustic sensing (DAS). DAS is used commercially for pipeline leak detection, perimeter security, powerline fault detection, geophysical monitoring, and transportation flow monitoring [30-33]. The measurements made by DAS systems are typically presented as unitless waveforms proportional to acoustic signals or particle velocity. This study shows that the measurements made with $\phi$-OTDR can be interpreted as dynamic strain and are useful for SHM. This makes long distance DDFOS for SHM possible using $\phi$-OTDR.

Both DDFOS technologies used in this study rely on Rayleigh scattered light within an optical fiber to make measurements. In fiber optic cables, inhomogeneities due to variations in refractive index, changes in waveguide geometry and local inhomogeneities that exist naturally in the glass fiber cause Rayleigh scattering [34]. These scattering points are distributed throughout the fiber core so densely that the scattering process is continuous along the fiber length. Some of this scattering occurs in the opposite direction of the incident light and is guided back to the beginning of the fiber. This is extremely useful for distributed sensing because the returning light can be analyzed, making the entire length of the fiber a sensing element capable of providing spatially continuous data.

\subsubsection{OFDR}

In OFDR, a laser with variable frequency is used to send a swept pulse of light into the fiber. Each point in the fiber has a unique scattering profile for both the intensity and frequency of light that it reflects. This creates a Rayleigh backscatter spectrum (RBS) for each point along the fiber. The frequency shift of the RBS is linearly related to the strain in the fiber at the scattering location. Since this change can be observed for very small lengths of fiber, extremely small spatial resolutions $(<1 \mathrm{~mm})$ are possible. However, the length of a sensing fiber is governed by the tuning speed and range of the laser. Therefore, the possible sensing distance is typically limited to $50 \mathrm{~m}$ for dynamic sensing [35]. Measurement frequency can vary from $250 \mathrm{~Hz}$ for a $2.5 \mathrm{~m}$ fiber to $20 \mathrm{~Hz}$ for a $50 \mathrm{~m}$ fiber. In this work, a Luna Innovations ODiSI6000 commercial OFDR system was used with a spatial resolution of $2.6 \mathrm{~mm}$ and a measurement frequency of $25 \mathrm{~Hz}$. The total sensing cable length was $50 \mathrm{~m}$.

\subsection{2 $\phi$-OTDR}

$\phi$-OTDR is the comparison of phase of Rayleigh backscatter originating from separate regions of a fiber [19]. This change in phase is directly proportional to strain in the region of the fiber between the compared Rayleigh backscatter [6]. The length of this region is referred to as the gauge length. The gauge length directly determines the localization ability of the $\phi$-OTDR system. The gauge length is different than the readout interval, which is the longitudinal spacing of measurements. In this study, an Optasense ODH-4 interrogator was used with a gauge length of $2 \mathrm{~m}$, a readout spacing of $1 \mathrm{~m}$ and an acquisition rate of $4 \mathrm{kHz}$. Measurement rates of up to $100 \mathrm{kHz}$ are possible, but for this study and most infrastructure applications, much slower acquisition is needed. The maximum sensing range of the $\mathrm{ODH}-4$ interrogator used in this study is $10 \mathrm{~km}$, which is 200 times larger than that of the OFDR system.

Both technologies detect mechanical changes in a sensing fiber due to externally applied strain and thermal expansion [21]. Though theoretically present in the measured information, the thermal effects can be ignored in this case. Data are acquired over such a short period of time in a laboratory setting that temperature changes are negligible.

\section{Experimental configuration and progression}

A model wind turbine tower was constructed to emulate the behavior of a full-scale tower. Flanged pipe sections were chosen due to their low thickness-diameter ratio. The cross section of the flanged pipe was chosen to have an 
inner diameter of $30.810 \mathrm{~cm}$, a thickness of $0.365 \mathrm{~cm} \mathrm{(10}$ gage), and an outer flange diameter of $38.43 \mathrm{~cm}$. The bolt pattern on the flanges consisted of 8 bolt holes equally radially spaced on the flanges with a bolt centerline diameter of $35.56 \mathrm{~cm}$. Six pipe sections, $1.22 \mathrm{~m}$ long each, were used to construct the $7.32 \mathrm{~m}$ tower. Each flange had slots cut $90^{\circ}$ apart up against the pipe body to allow the fiber optic sensing cables to be threaded through the joints while remaining attached to the tower. The flanges were continuously welded on the inside of the pipe and tack welded on the outside of the pipe. The pipe sections were connected to each other with $0.794 \mathrm{~cm}$ bolts using a torque gun.

The fully constructed tower is shown in Fig. 1. The tower was welded at the top and bottom to steel plates. The top plate was used to mount a vibration generator and the bottom plate was used to bolt the tower to a strong floor. The vibration generator was bolted to the top plate using $2.54 \mathrm{~cm}$ bolts tightened with a torque gun. To ensure proper load transfer, steel gusset stiffeners were attached to the base and first flange above the base. 10 steel stiffeners were attached to the base of the tower. They were placed asymmetrically, with 5 clustered at the north and south extent of the tower. Similarly, the first flange was asymmetrically stiffened, with 6 stiffeners clustered at each the north and south extent. These orientations stiffened the north-south axis more than the east-west direction. The vibration generator was configured to create a 1-D sinusoidal force in the north-south direction. The stiffeners were placed for safety to prevent tower collapse caused by local yielding where the maximum bending moment would be experienced during forced vibration.

The vibration generator consisted of two steel baskets that spin opposite one another in the horizontal plane. This specific machine was designed for testing full-scale structures under dynamic loads and its design is detailed in [36]. The rotation of the two baskets generates a 1-D sinusoidal force. The maximum output inertial force exerted by this type of vibration generator is a function of the mass and speed of rotation of the baskets. The mass of the vibration generator and top plate were measured to be $245 \mathrm{~kg}$ and $150 \mathrm{~kg}$, respectively.

This vibration generator was used because the configuration mimics the mass distribution of a wind turbine and true dynamic loading could be created to resonate the structure, as opposed to controlled displacement. The mass of the vibration generator and mounting plate simulates the mass of the nacelle, gearbox, generator, rotor hub and rotors of a full-scale wind turbine. When the vibration generator is off, free vibration tests were conducted by displacing the top of the tower to directly excite the first-mode natural frequency. The vibration generator was only turned on to resonate the
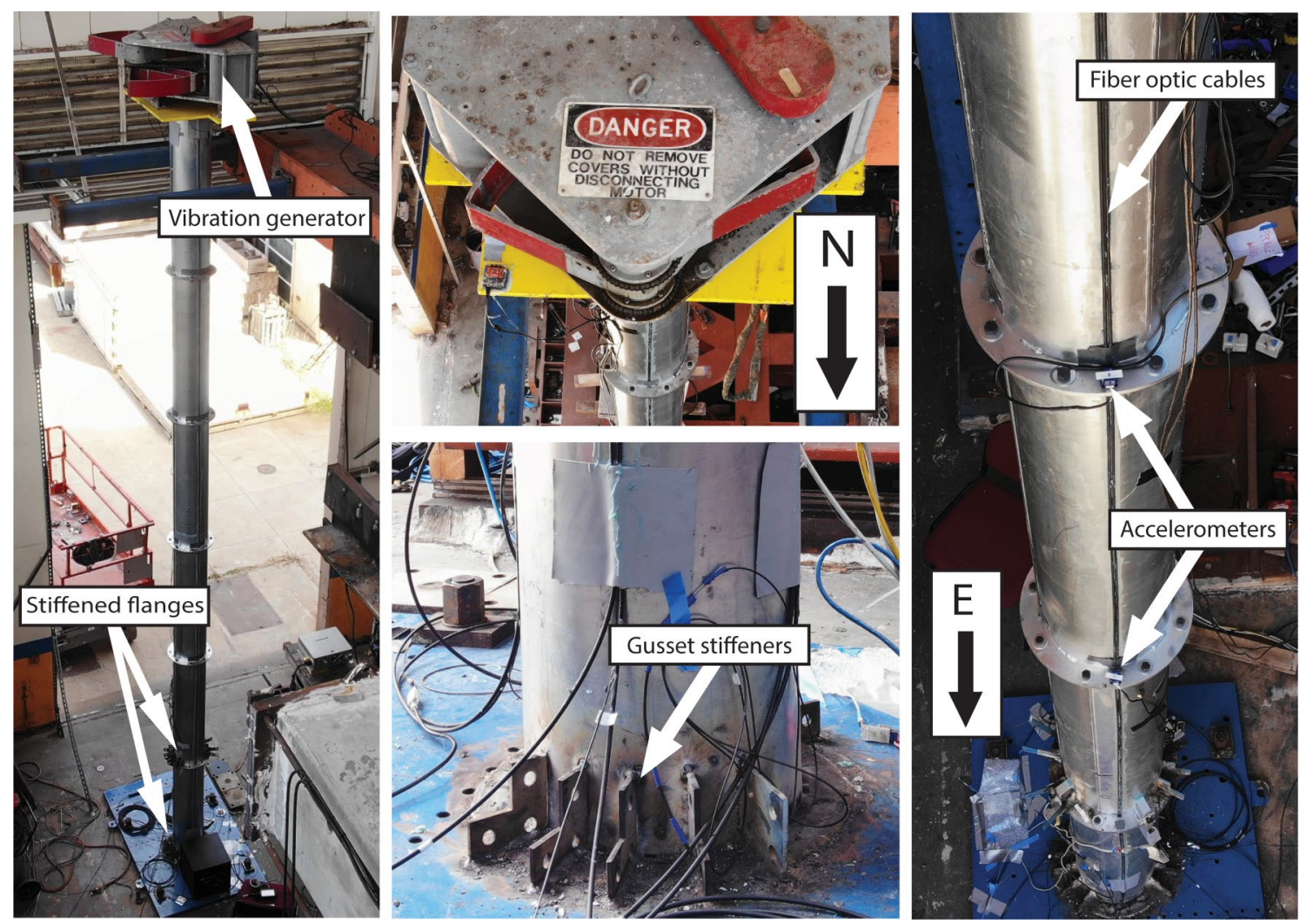

Fig. 1 Photographs of the experimental configuration 


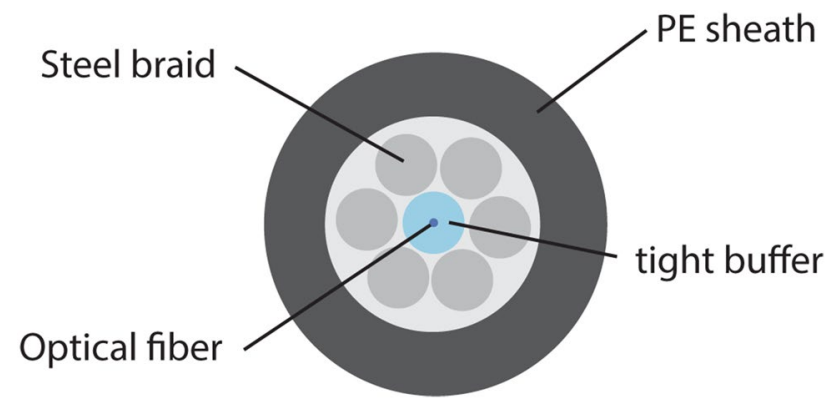

Fig. 2 Cross section of NZS-DSS-C02 distributed strain sensing cable

structure and cause damage to be detected by the employed sensing system, so the forcing magnitudes produced were not meant to simulate typical wind loading.

NanZee Sensing NZS-DSS-C02 single mode, tightly buffered fiber optic cables were used for OFDR and $\phi$-OTDR measurement. The cross section of this cable is shown in Fig. 2. The cable is made of a tightly buffered single-mode core wrapped inside six helically-wound steel braids. The steel braids are inside a rugged polyethylene (PE) sheath.

The cables were epoxied continuously to the tower on north, south, east, and west axes using 3 M DP8010 plastic structural adhesive. The sensing cables were threaded through slots in the flanges and were unbonded $1.25 \mathrm{~cm}$ above and below each flange. The slots were directly against the tower body, so the cables remained flush against the structure continuously. Epson M-A351 accelerometers were adhered to the flanges and the top plate using an industrial adhesive tape, seven in total were used. The accelerometers were placed on the top of the flange at each joint along the east axis. Figure 3 shows instrumentation plan of the tower as viewed from the east.

First, the tower was manually displaced at the top towards the north by $15 \mathrm{~cm}$ and allowed to vibrate freely. This test was completed when all bolts were tightened, when one bolt was loosened, and when two bolts were loosened. The bolts that were loosened are indicated in Fig. 4.

After the sequence of free vibration tests, the bolts were all re-tightened and the tower was vibrated using the vibration generator. The generator was ramped from approximately $0.3 \mathrm{~Hz}$, its idle speed, to approximately $3 \mathrm{~Hz}$. The first-mode natural frequencies of the north-south and east-west axes were both less than $3 \mathrm{~Hz}$, so the tower briefly was excited at its resonant frequency during each ramp. The ramping took approximately $45 \mathrm{~s}$ each, and the generator was immediately shut off when it finished speeding up. This process was repeated three times.

To compare the DFOS results with the industry accepted modal analysis methods, the dynamic properties of the tower were first calculated using the accelerometer

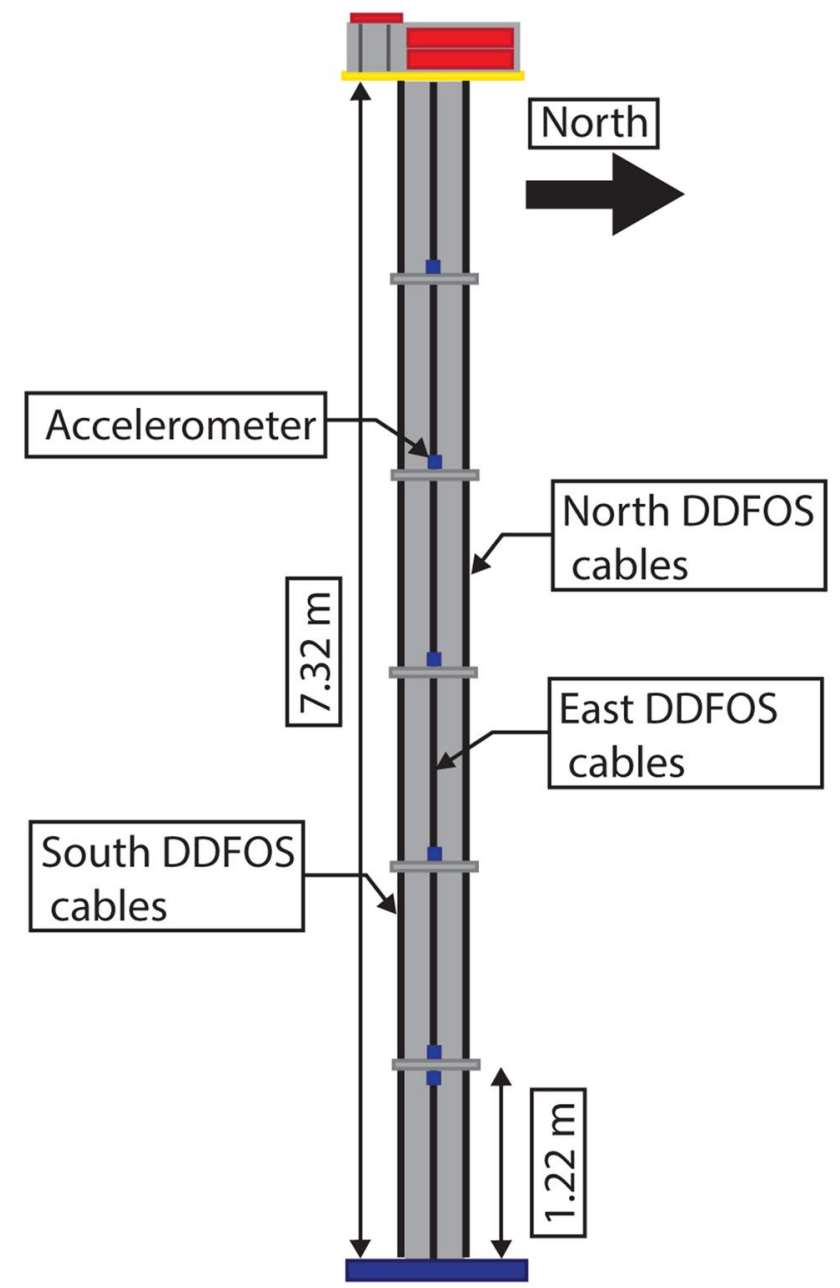

Fig. 3 Instrumentation plan of the model tower

data for each test. The damping ratios were calculated using the log-decrement method, which is valid for small damping ratios. Also, when the damping ratio is sufficiently small, the damped and undamped natural frequencies can be considered equal. The natural frequencies can then be determined using the accelerometer data by calculating the power spectrum as:

$\operatorname{PS}[m]=\sum_{n=0}^{N} r_{x x}[n] e^{-\frac{j 2 \pi m n}{N}} \quad m=0,1,2,3 \ldots N$,

where $r_{x x}$ is the autocorrelation of the time series.

It was observed that the tower possessed two clear firstmode natural frequencies because of the asymmetrically stiffened base and first flange. The north-south axis possessed a natural frequency slightly higher than the east-west axis. Each natural frequency and damping ratio as measured with the Epson M-A351 accelerometers during the free vibration tests are shown in Table 1 . The damping of tower is not significantly changed by bolt loosening. The variability 


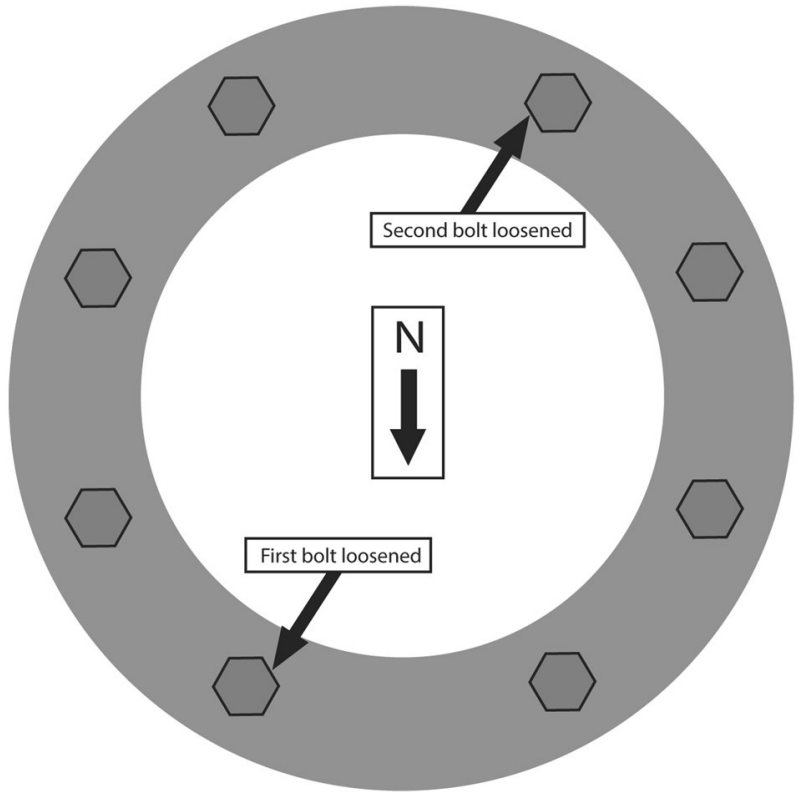

Fig. 4 Schematic diagram of the locations of the bolts loosened during testing

Table 1 Accelerometer results from free vibration test

\begin{tabular}{llll}
\hline Testing condition & $\begin{array}{l}\text { East-west natu- } \\
\text { ral frequency } \\
(\mathrm{Hz})\end{array}$ & $\begin{array}{l}\text { North-south } \\
\text { natural frequency } \\
(\mathrm{Hz})\end{array}$ & $\begin{array}{l}\text { Damping } \\
\text { ratio (\%) }\end{array}$ \\
\hline Bolted tower & 1.21 & 1.41 & 0.49 \\
One bolt loosened & 1.17 & 1.39 & 0.44 \\
Two bolts loosened & 1.16 & 1.38 & 0.46 \\
\hline
\end{tabular}

of the calculated damping ratios is considered within the repeatability of the test setup.

\section{Interpretation of free-vibration datasets}

\subsection{OFDR}

OFDR can measure strain with high spatial resolution, but limited range, making it ideal for laboratory-scale experiments. An example strain profile from the north side of the tower at a discrete time during the free vibration test is shown in Fig. 5. During this test, the tower was displaced in the north direction at the top by $15 \mathrm{~cm}$ and allowed to vibrate freely. All bolts were tight during this example. The strain profile reveals localized details of the strain distribution. The strain peaks are located at the flange connections of the tower. Strain localizes at these connections, reaching values over $400 \mu \varepsilon$ for this test, and is less than $50 \mu \varepsilon$ elsewhere. The peaks in the strain stretch

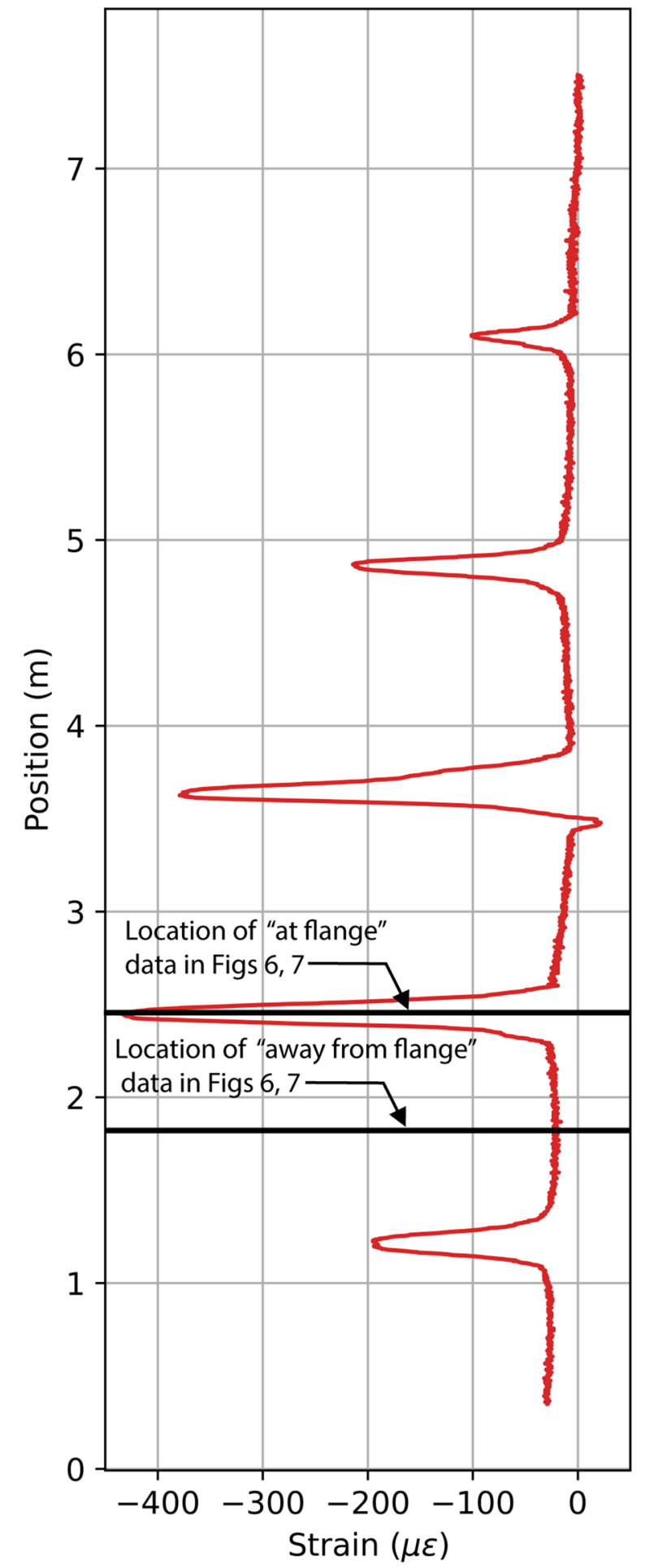

Fig. 5 OFDR strain profile of tower under free vibration with all bolts tight

over $0.25 \mathrm{~m}$ for the lowest three flanges and $0.1 \mathrm{~m}$ for the top two flanges. This indicates that not only do the lower flanges exhibit more strain, but the deformation is exhibited over a larger distance. 
Time series measurements can also be evaluated at specific locations, or channels, within the OFDR data. Figure 6 shows two of these time series for channels located at the flange and away from the flange, the exact locations are shown as black lines in Fig. 5. These time series are from the north side of the tower during free vibration. As shown, the signals are different in composition. The time series located away from the flange experiences double the amount of compression as it does tension, while the data from the flange location has a higher amplitude on the tension side. So, it can be observed directly that most of the extension associated with the tower deflecting towards the south is accommodated at the flanges, while the tower body away from the flange experienced compression when the tower deflects towards the north.

A frequency domain analysis can be conducted to evaluate the natural frequencies of the structure. Figure 7 shows the power spectrums for channels at and away from a flange.

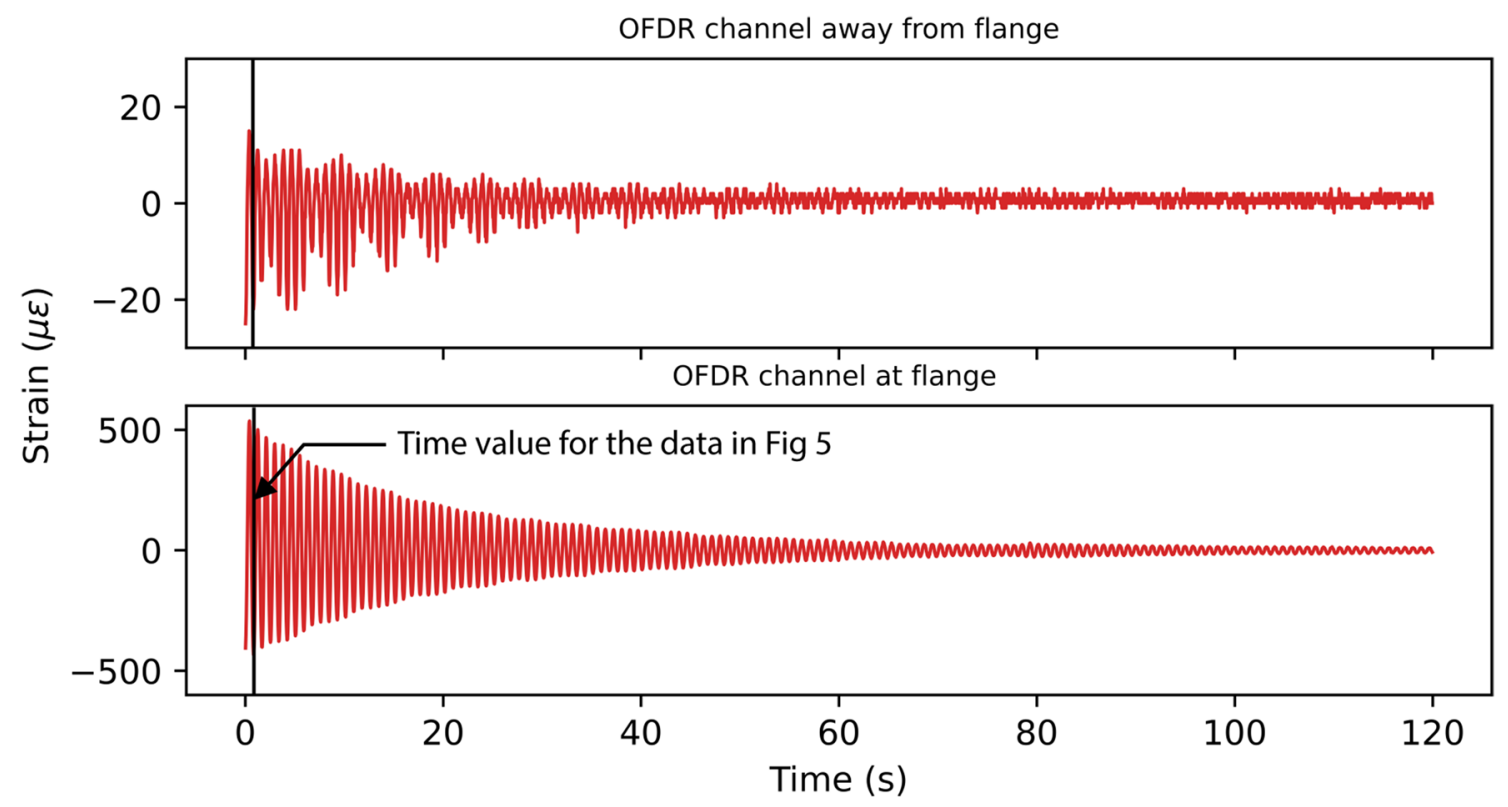

Fig. 6 OFDR time series from the north side of the tower during free vibration

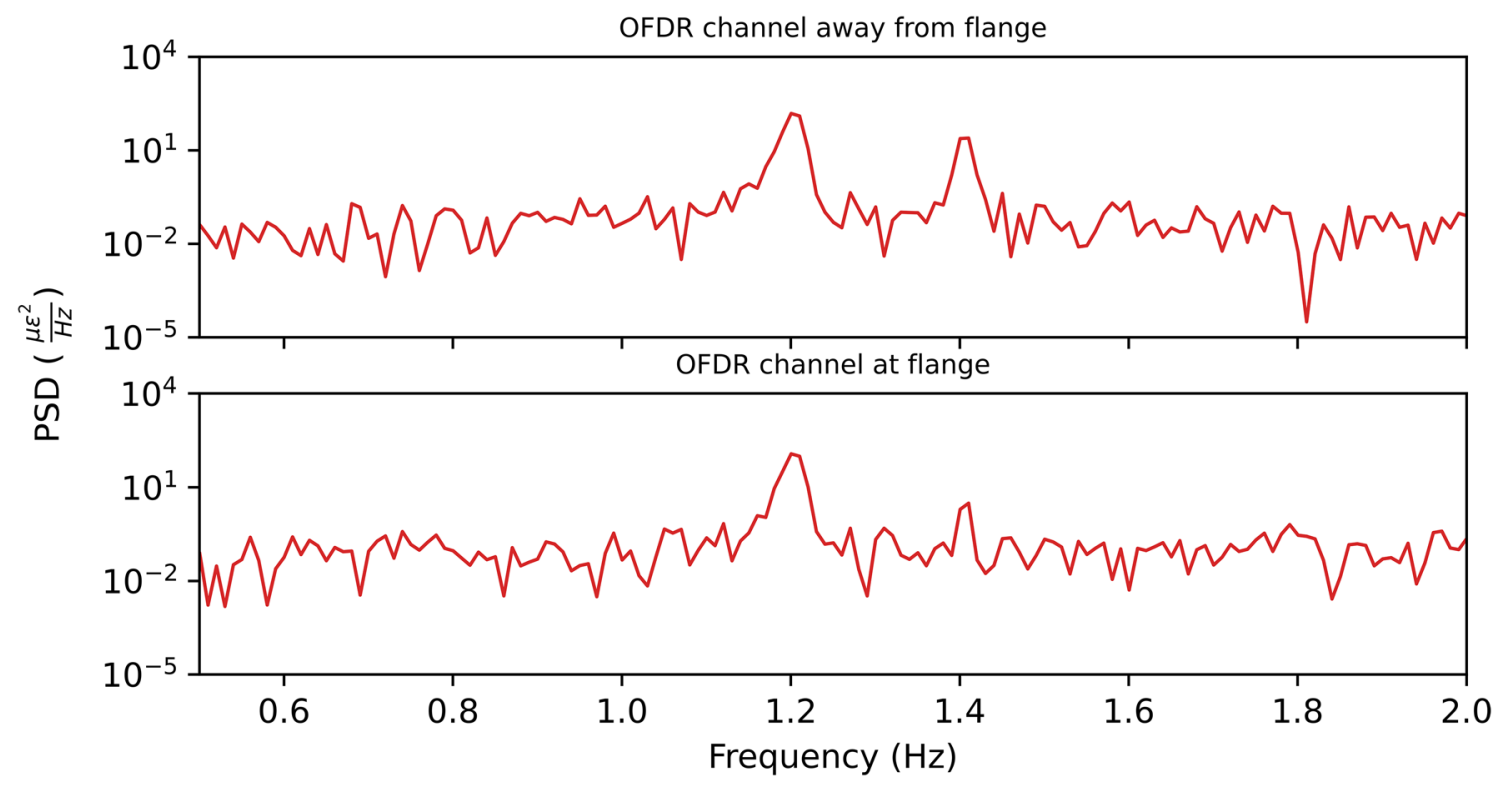

Fig. 7 Power spectrums for channels at and away from a flange 
Both dominant frequencies can be clearly seen in these representations which match the accelerometer data with values of 1.21 and $1.41 \mathrm{~Hz}$. The signal-to-noise ratio (SNR) can also be examined for both channel locations. Away from the flange, the SNRs are $31.3 \mathrm{~dB}$, and $24.3 \mathrm{~dB}$ for the two respective frequencies, and at the flange they are $52.6 \mathrm{~dB}$ and $27.4 \mathrm{~dB}$. In each case, the strength of the signal is adequate to determine the natural frequencies of the structure.

\section{$3.2 \phi$-OTDR}

$\phi$-OTDR measures changes in optical path length across a gauge length of a sensing cable. This measurement is in radians of the light wave. The data are converted to meaningful strain measurement using the equation [6]:

$\mathrm{d} \varphi=\frac{4 \pi n G \xi}{\lambda} \varepsilon$

where $\mathrm{d} \varphi$ is the optical phase shift in radians, $\lambda$ is the operational optical wavelength in vacuum, $n$ is the refractive index of the sensing fiber, $G$ is the gauge length of the $\phi$-OTDR system, $\xi$ is the photo-elastic scaling factor, and $\varepsilon$ is the strain.

Typical $\phi$-OTDR strain time-histories are shown in Fig. 8 for readout channels located on the north and south sides of the tower during the same free vibration test used for Figs. 5, 6 and 7. As expected, the north and south sides are $180^{\circ}$ out of phase with each other and have similar amplitude and damping behavior.

The time series can be evaluated for damping behavior and natural frequencies present in the same way as the accelerometer and OFDR data. This result is shown in Fig. 9. When the power spectrum is examined, there are two prominent peaks visible at 1.21 and $1.41 \mathrm{~Hz}$. The SNR of these peaks are 47.5 and $30 \mathrm{~dB}$, respectively. A high-pass filter with a cut-off frequency of $0.5 \mathrm{~Hz}$ was used. This was to eliminate the optical drift inherent to $\phi$-OTDR data without affecting the quantitative dynamic strain measurement at slightly higher frequencies. It should be noted that it is possible to use a lower cut-off frequency if the natural frequencies of interest are lower.
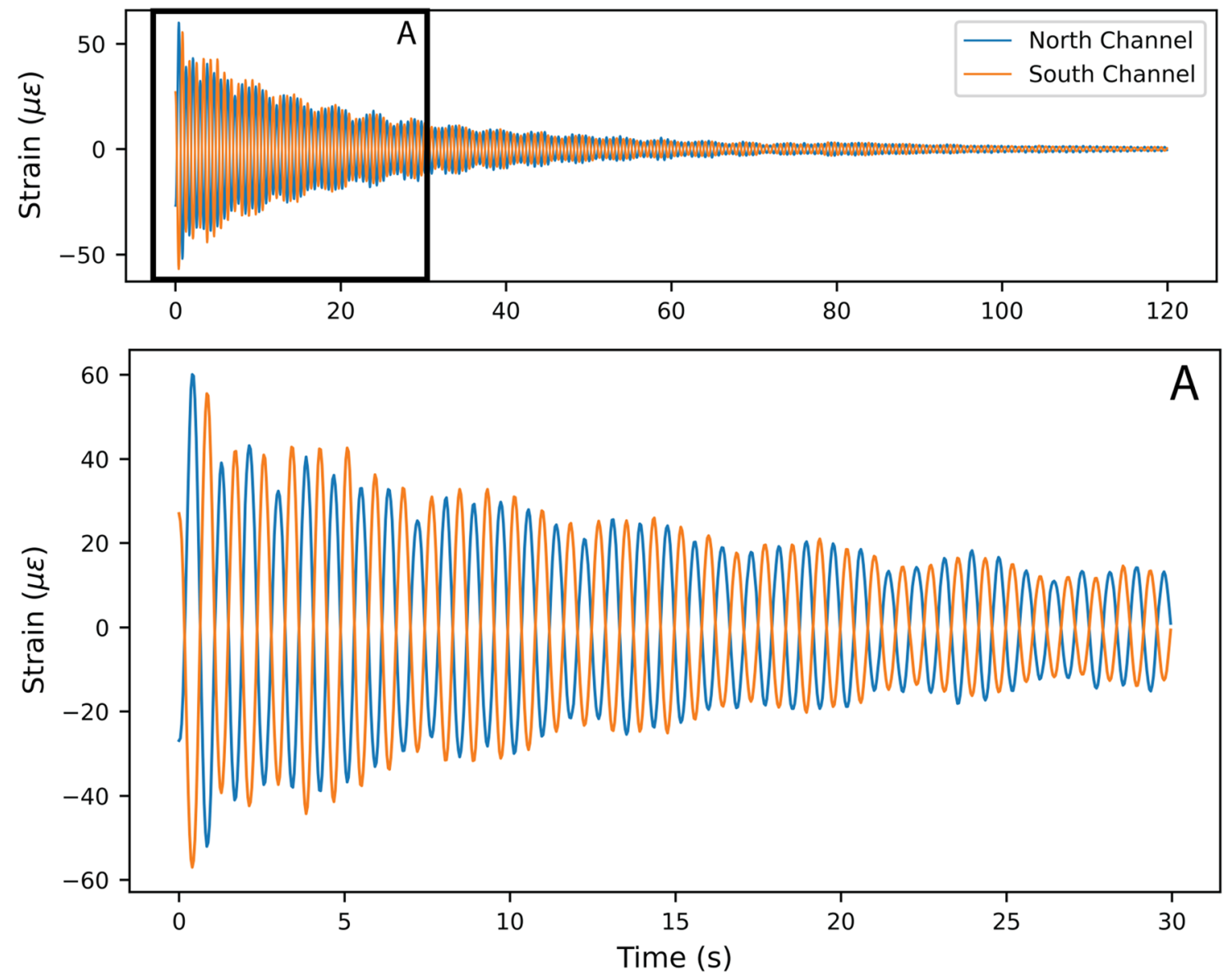

Fig. 8 Strain time series from opposite $\phi$-OTDR channel locations during a free vibration test, with a closeup to show the phase difference 


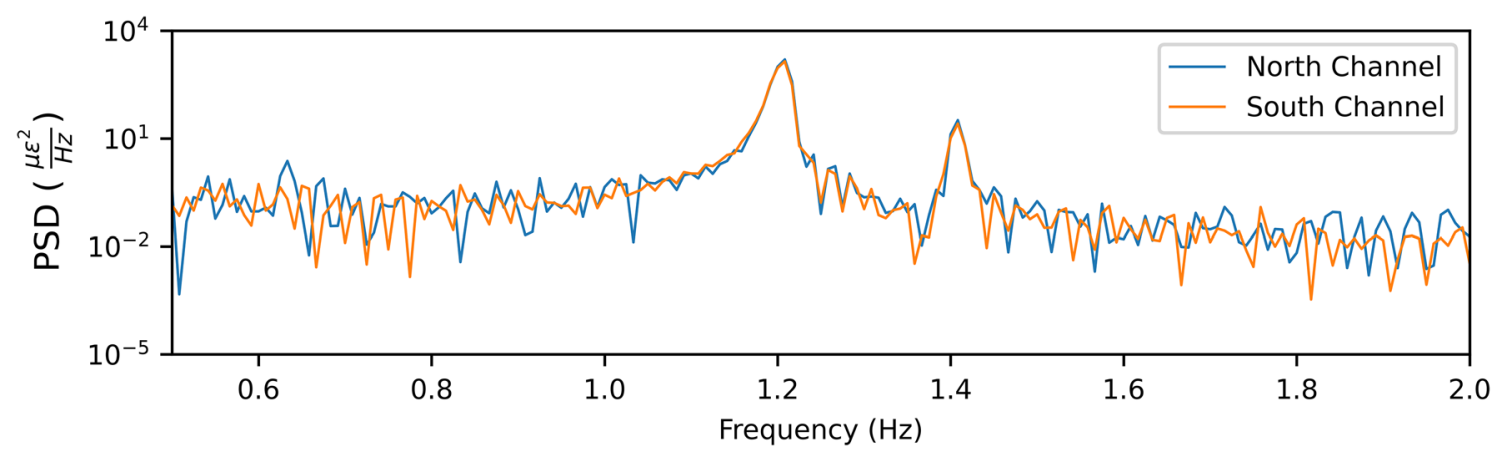

Fig. 9 Power spectrum of free vibration $\phi$-OTDR time series data

\section{Loose bolt and damage detection}

The DDFOS technologies have been evaluated for their ability to detect damage both directly and through a shift in the natural frequencies of the structure.

\subsection{Direct detection of loose bolts}

Directly identifying opening at the flanges on the lab specimen is straight forward for OFDR because of its fine spatial resolution. $\phi$-OTDR, on the other hand, has a larger spatial resolution of $2 \mathrm{~m}$. This makes localization of phenomena on a laboratory specimen challenging. Only a few independent readouts are possible on the length of tower examined in this study. Nonetheless, localized changes can be determined but must be visualized on a channel-by channel basis. The location of readout channels is especially important for $\phi$-OTDR because each channel represents the total strain from $\pm 1 \mathrm{~m}$ from that location.

\subsubsection{OFDR}

OFDR is capable of detecting strain at flanges with loose bolts directly. Figure 10 shows the directly measured strain during the free vibration tests with conditions of no loose bolts, one loose bolt and two loose bolts. Both the north and south strain profiles are shown for the same time indicated in Fig. 6, which corresponds to one wavelength of vibration from the time of release. Due to the difficulty in controlling the vibrational mode and manually applying the displacement, Fig. 10 also shows the strain distribution normalized by its integral. This plot gives an important representation of the change in deformation mechanism between the three conditions.

As expected, there are large strains exhibited at the first flange where the bolts were loosened. The strain is largest on the north side of the tower when the first bolt is loosened. When the second bolt is loosened the south strain increases at the first flange. The percentage of total deformation accounted for by the first flange increases as well. The flanges where bolts were not loosened account for larger proportions of the total deformation when there is no damage. This proportion decreases as the strain is focused at the first flange.

The spatially continuous strain data can be integrated according to the relation:

$u(x)=\int \varepsilon(x) \mathrm{d} x$,

where $u(x)$ is the cumulative displacement, and $\varepsilon(x)$ is the strain in the axial direction of the sensing cable.

The strain data are numerically integrated, with $\mathrm{d} x$ approximated as the readout interval of the OFDR measurements. This can be done for the regions surrounding the flanges to determine flange opening. Figure 11 shows the flange opening computed in this way, normalized by the sum of all flange openings. Like Fig. 9, the opening at flange 1 contains a larger proportion of the total flange openings as bolts are loosened. The very small magnitude of these openings should be noted. The smallest measured opening was at flange 5 and measured $15 \mu \mathrm{m}$, while the largest was at flange 1 and measured $138 \mu \mathrm{m}$.

\subsection{2 $\phi$-OTDR}

Due to the limitations of the laboratory scale for $\phi$ -OTDR, one readout channel is examined, the gauge length of which spanned the joint where bolts were loosened. Figure 12 shows this readout channel for both the north and south sides of the tower during the free vibration test. As shown, there is a clear increase in strain amplitude. For the north side, the maximum strain values recorded after one wavelength of oscillation were 57, 81 and $86 \mu \varepsilon$ for the cases of no loose bolts, one and two loose bolts respectively. For the south side of the tower, the strain amplitudes were 61,82 and $92 \mu \varepsilon$ for the respective conditions. These strains correspond to 


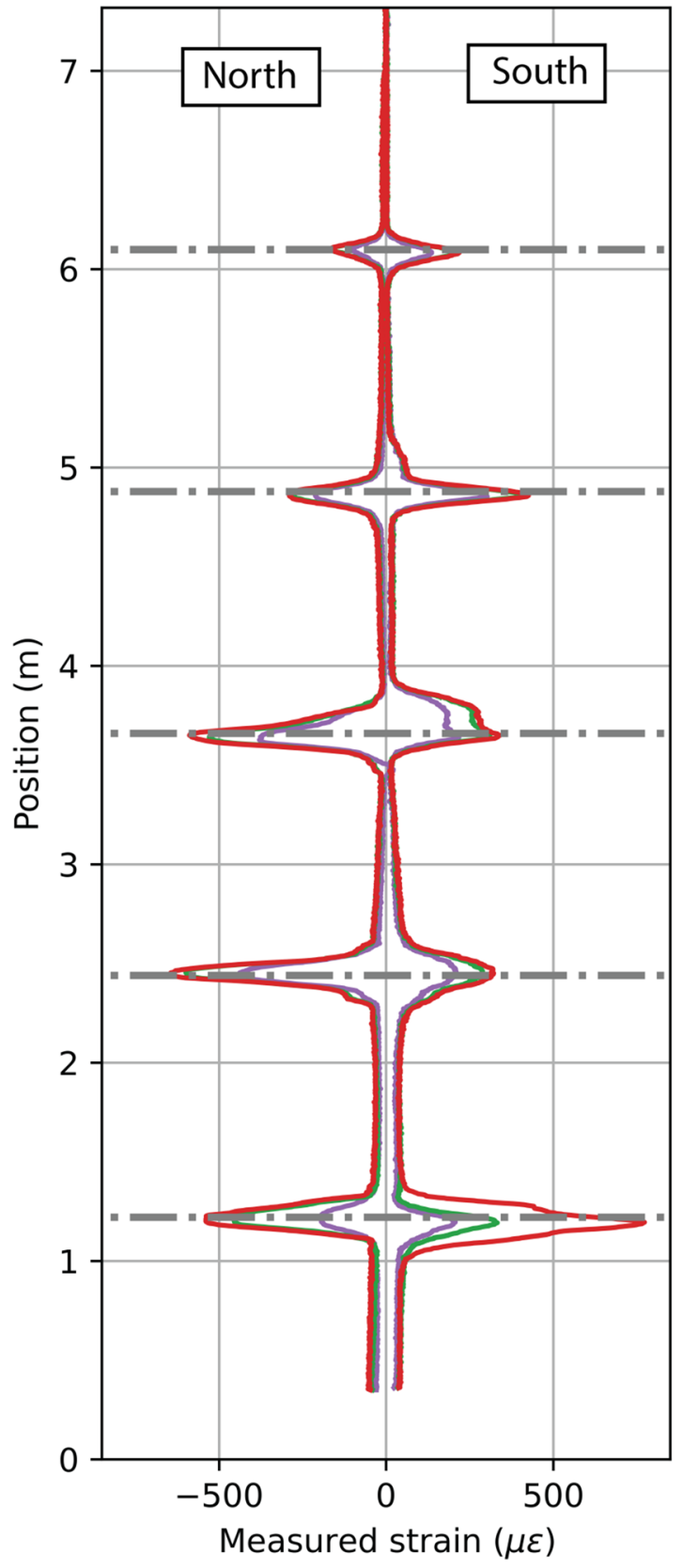

Fig. 10 Measured and normalized strain profiles when loosening bolts

elongations in the sensing fiber between 117 and $175 \mu \mathrm{m}$ for the length of fiber spanning the flange.

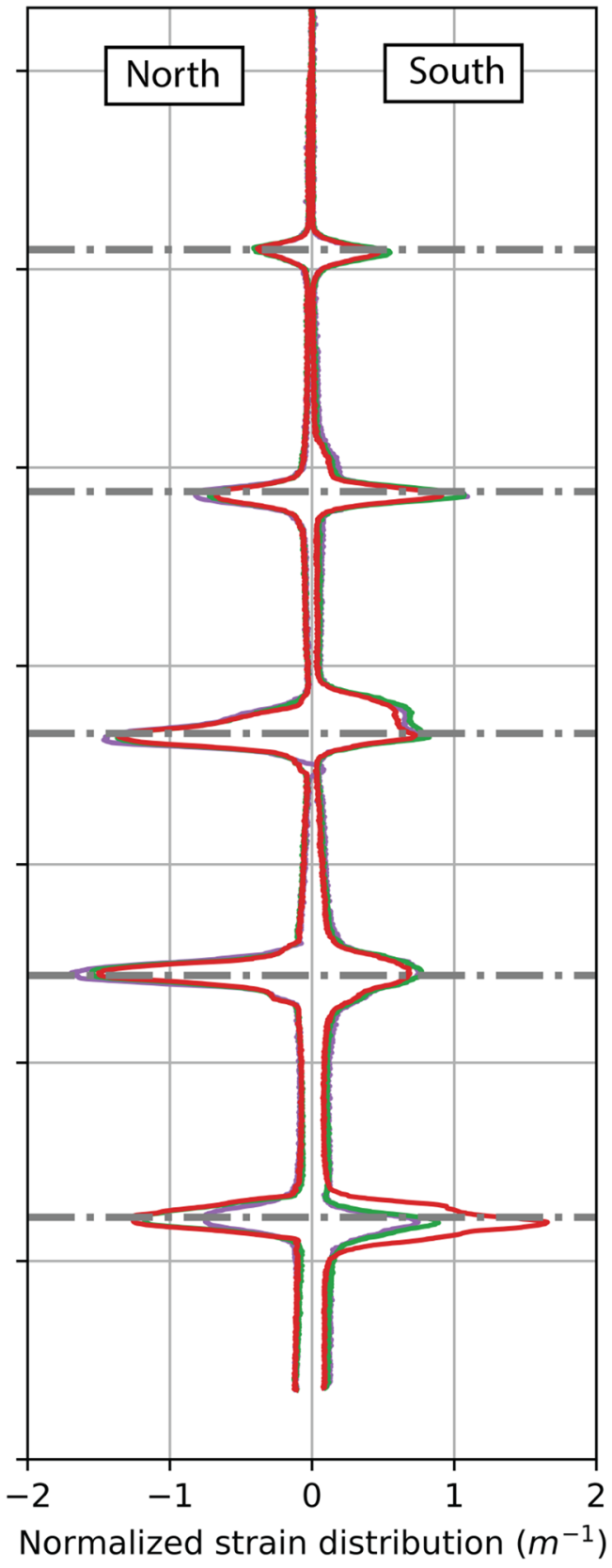

\subsection{Loose bolt and damage detection by change in natural frequency}

The natural frequencies of the tower can be measured directly using the time-series data from both OFDR and 


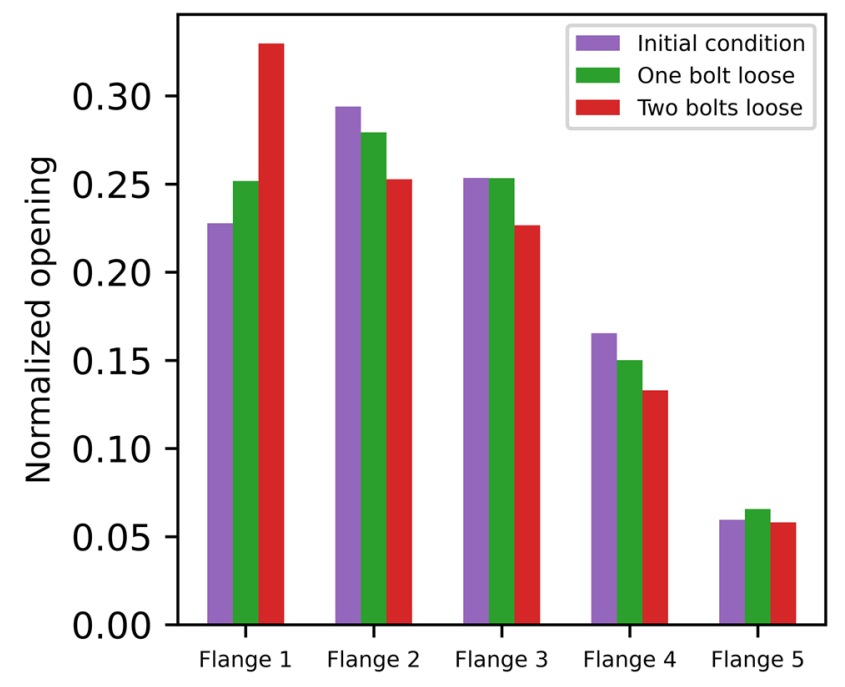

Fig. 11 Measured and normalized strain profiles when loosening bolts

$\phi$-OTDR. In this section, the results of two sets of tests are presented for both technologies; free vibration with varying bolt tightness and forced vibration that caused localized material yielding. Each damage state resulted in altered natural frequencies of the structure and the technologies are compared for their ability to measure the frequency shifts.

\subsubsection{Bolt loosening}

Spectra obtained with OFDR are displayed in Fig. 13 for channels located at and away from a flange during free vibration tests with bolt loosening. The power spectra of the strain data show a broadening across lower frequencies as bolts are loosened. Also, the peak natural frequency shifts downwards when bolts are loosened versus when they are not. Downward shifts occurred for both axes' first-mode natural frequencies and were calculated as identical values for channels at and away from a flange opening.

The stiffer north-south axis exhibited natural frequencies of $1.41,1.40$ and $1.39 \mathrm{~Hz}$ for each condition, while the east-west axis had frequencies of $1.21,1.18$ and $1.17 \mathrm{~Hz}$ for each respective condition of all bolts tight, one and two bolts loose. In addition to the shift in natural frequency, the width of the spectrum, specifically in the condition when two bolts were loosened, widen with a tail that stretches toward the lower frequencies.

The frequency information gathered by $\phi$-OTDR also shows frequency shifts during bolt loosing as well as similar broadening of the spectra when bolts are loosened. These results are shown in Fig. 14.

The peak frequencies for the stiffened axis were 1.41, 1.40 and $1.39 \mathrm{~Hz}$, while the peak frequencies for the unstiffened axis were 1.20,1.17 and $1.17 \mathrm{~Hz}$ for the cases of no bolts loose, one and two bolts loose, respectively.

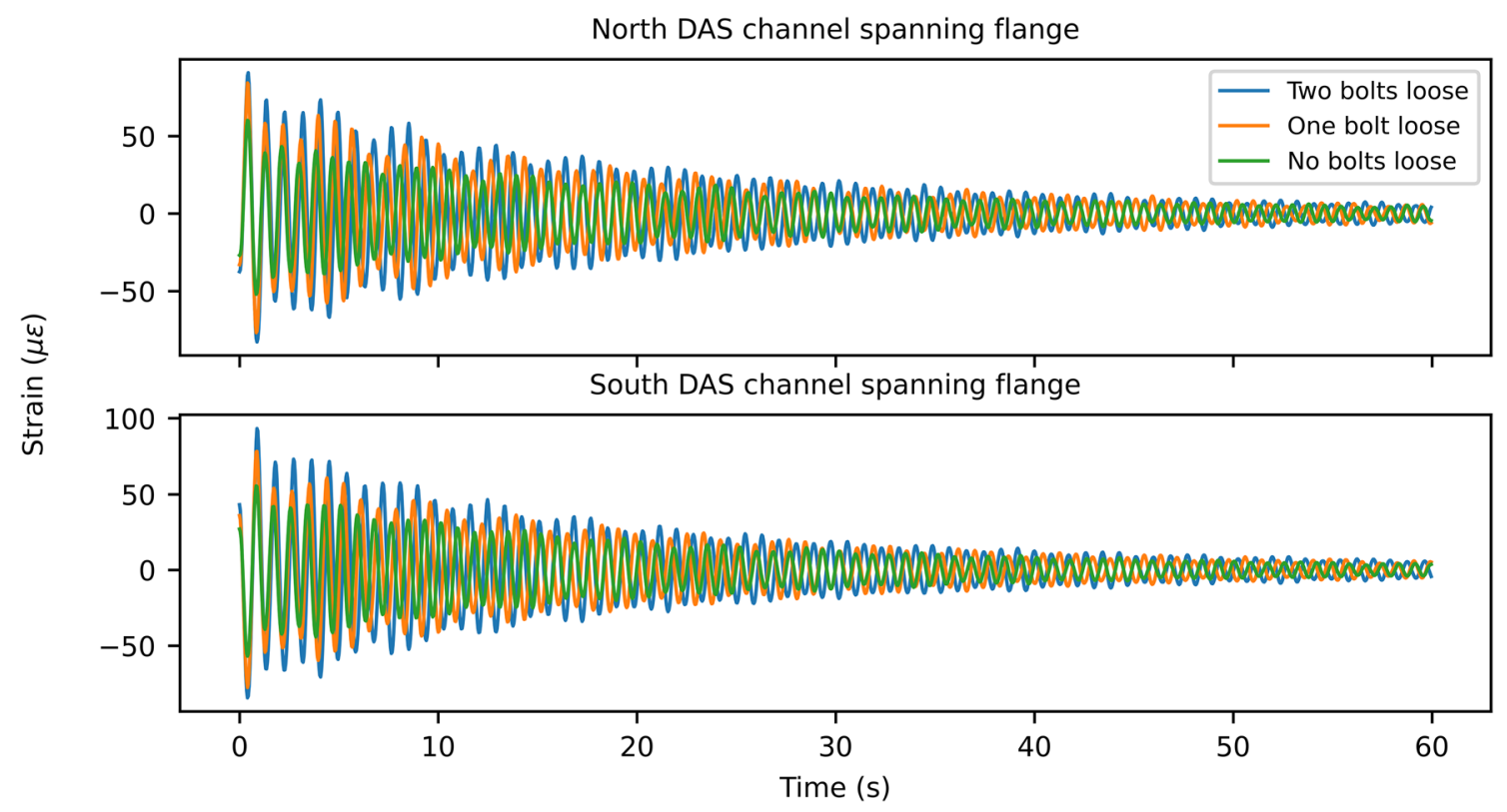

Fig. $12 \phi$-OTDR strain time-series for free vibration during three different damage states 


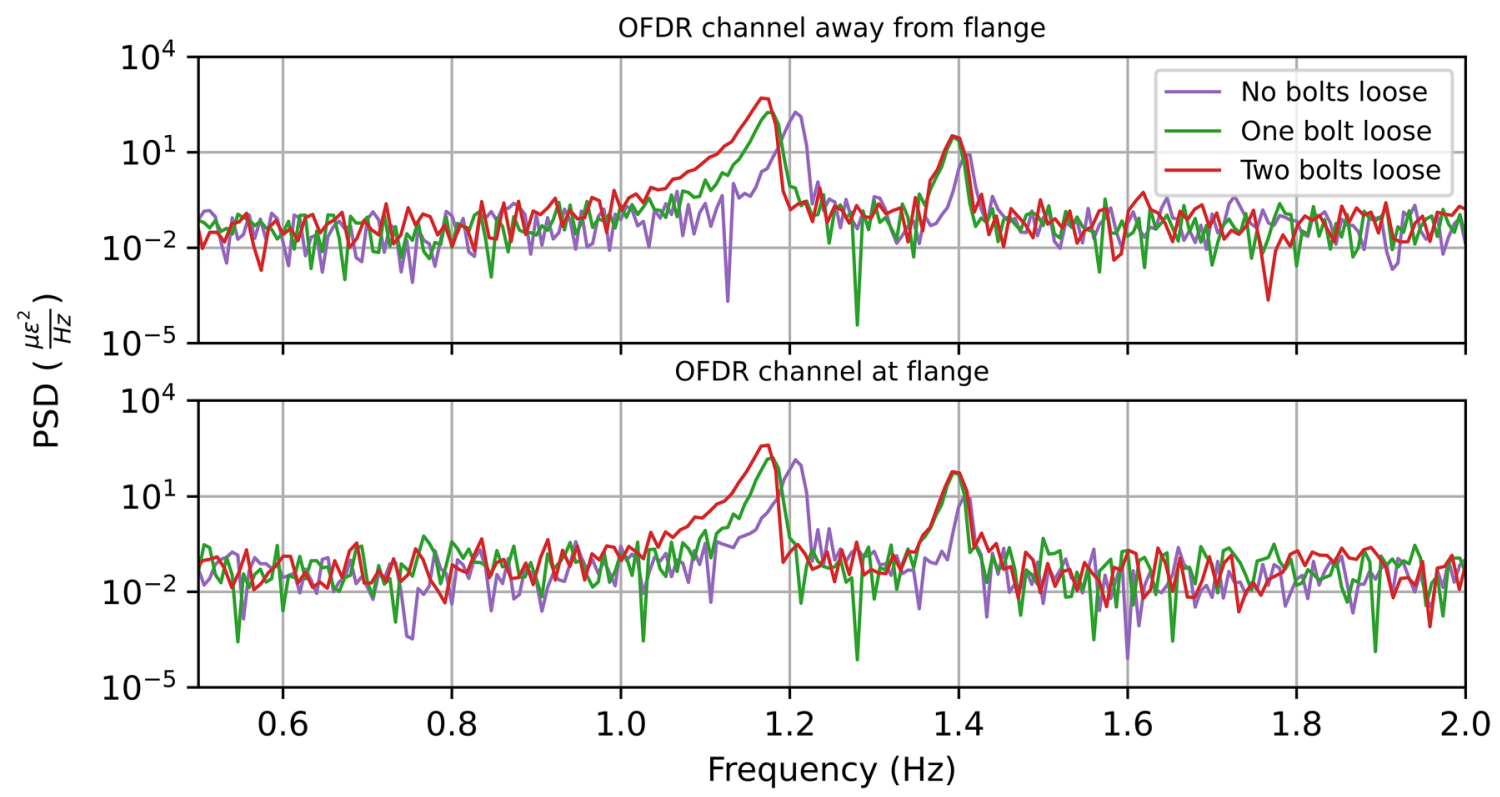

Fig. 13 Power spectra of OFDR strain time series measurements during free vibration with three different damage states

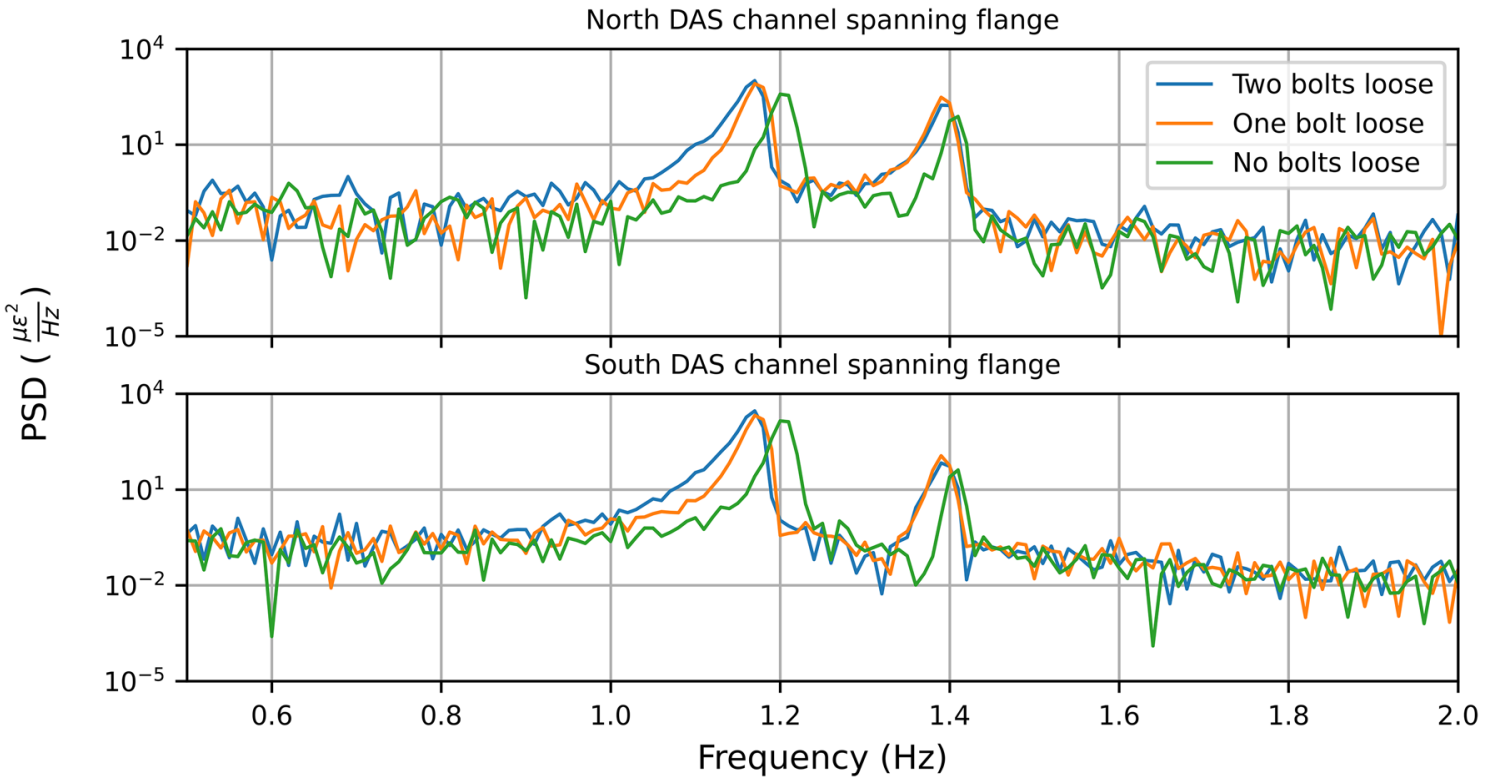

Fig. 14 Power spectra of $\phi$-OTDR strain time series measurements during free vibration with three different damage states

\subsubsection{Damage due to forced vibration}

After the bolt loosening tests, a similar comparison was conducted for the tower by vibrating it near its resonant frequency repeatedly with the vibration generator. The tower experienced localized material yielding at the first flange during the resonance testing. An example of this damage is shown in Fig. 15a, where the flange separation at the northern extent of the tower is shown. Figure 15b, c show stills from a forced vibration test, where the extent of the deflection can be seen to both the north and south.

The spectra were examined for both OFDR and $\phi$-OTDR before and after each test. Figure 16 shows the comparison of natural frequencies as determined by both technologies.

The natural frequencies match for almost every measurement. However, where the slight mismatching 

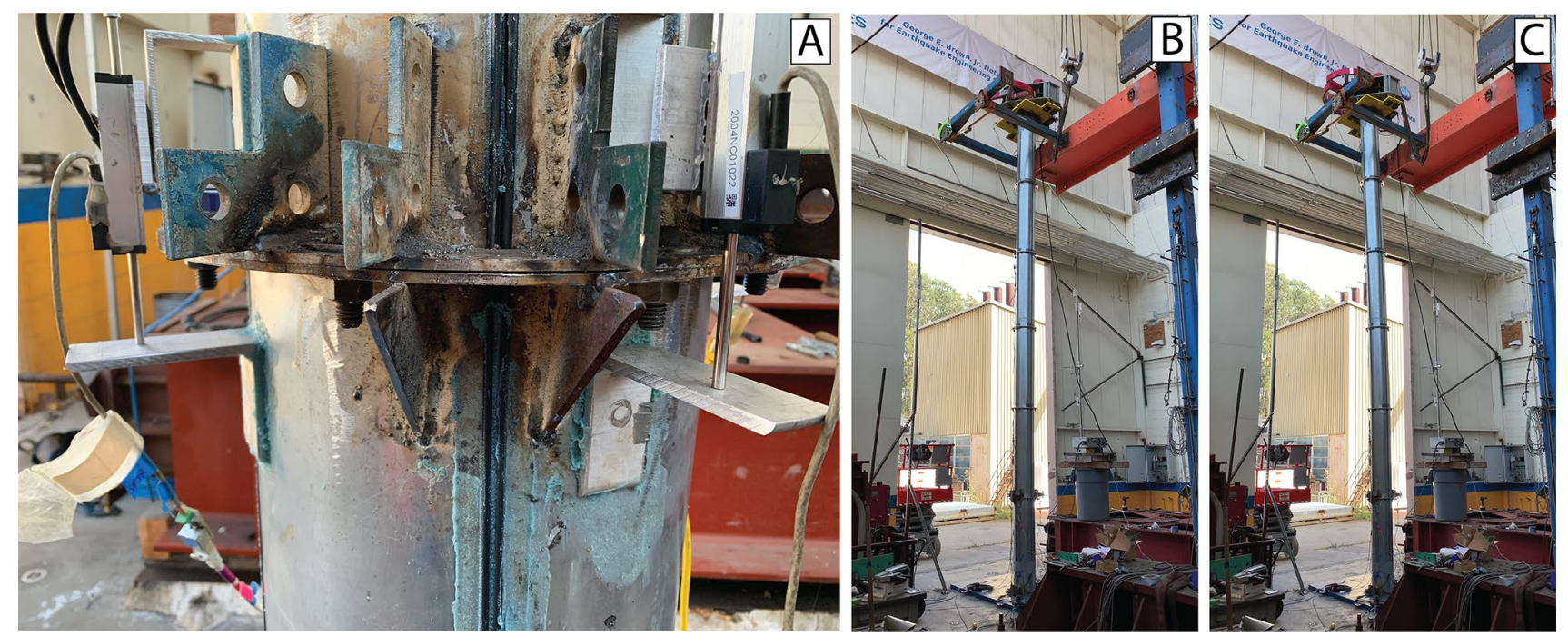

Fig. 15 a Flange separation at the northern extent of the tower after the first forced resonance; Tower deflecting during forced vibration to the south (b) and north (c)
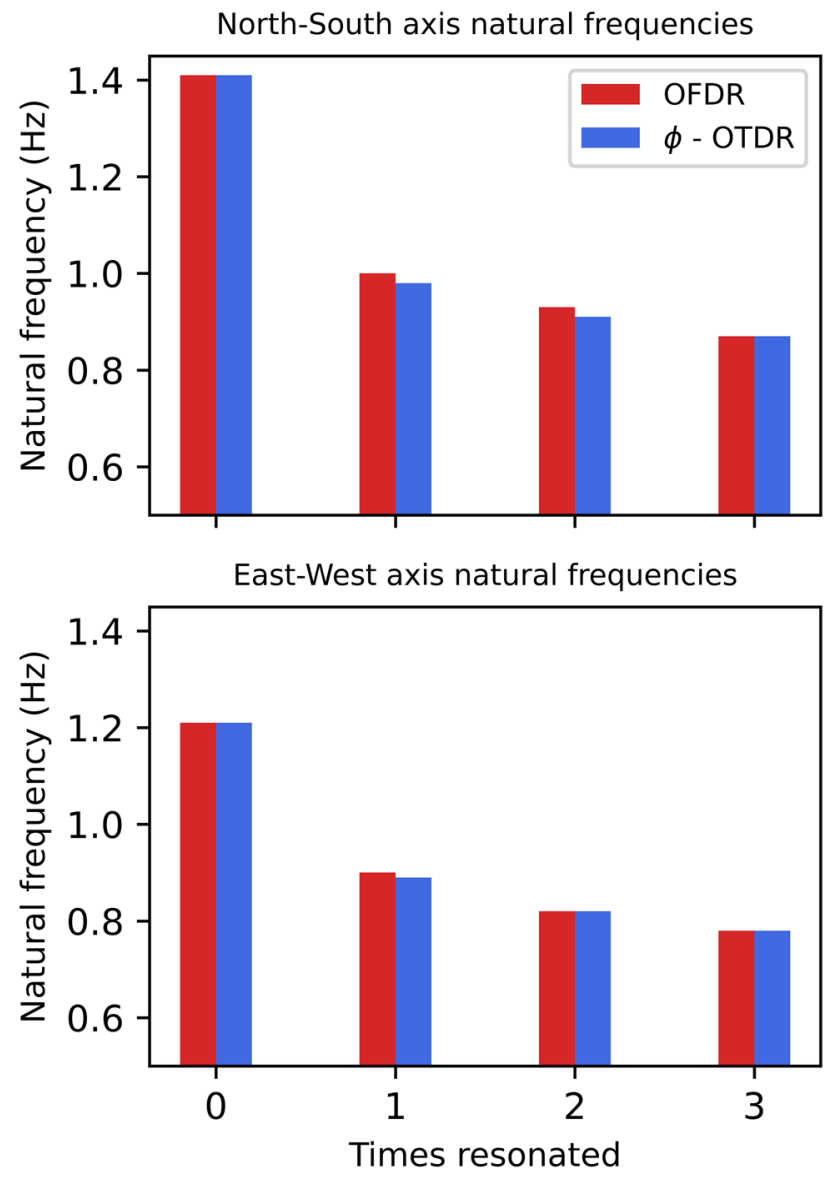

Fig. 16 Measured natural frequencies before and after each forced vibration test comes in is a matter of one frequency bin in the power spectrum. For consistency, the spectra were calculated with data sampled at $25 \mathrm{~Hz}$ for both technologies. This required decimation by a factor of 160 for the $\phi$-OTDR data. Then, 1000 datapoints of the time series were used to compute the power spectra. This process results in frequency resolutions of $0.0125 \mathrm{~Hz}$. The largest difference in natural frequency determination between the two technologies was one frequency bin, which can be attributed to using a relatively small number of samples for the calculation.

\section{Validation of $\phi$-OTDR as a viable SHM technique}

To validate the $\phi$-OTDR measurements, both datasets can be converted from strain with different gauge lengths to their equivalent cumulative displacement fields. This requires some understanding of the measurement principles used by each technology. In OFDR, strain readings are made for each $2.6 \mathrm{~mm}$ of fiber length. The cumulative displacements can be calculated by integrating spatially over the fiber length at each point in time, much as was done in the previous section to quantify the openings observed at the flanges during vibration. $\phi$-OTDR fundamentally measures the optical phase shift over a gauge length of the sensing fiber, $2 \mathrm{~m}$ in this study. This optical phase shift is then converted to a strain measurement. To compute the displacement field for $\phi$-OTDR, the direct measurement of optical phase is linearly scaled according to: 


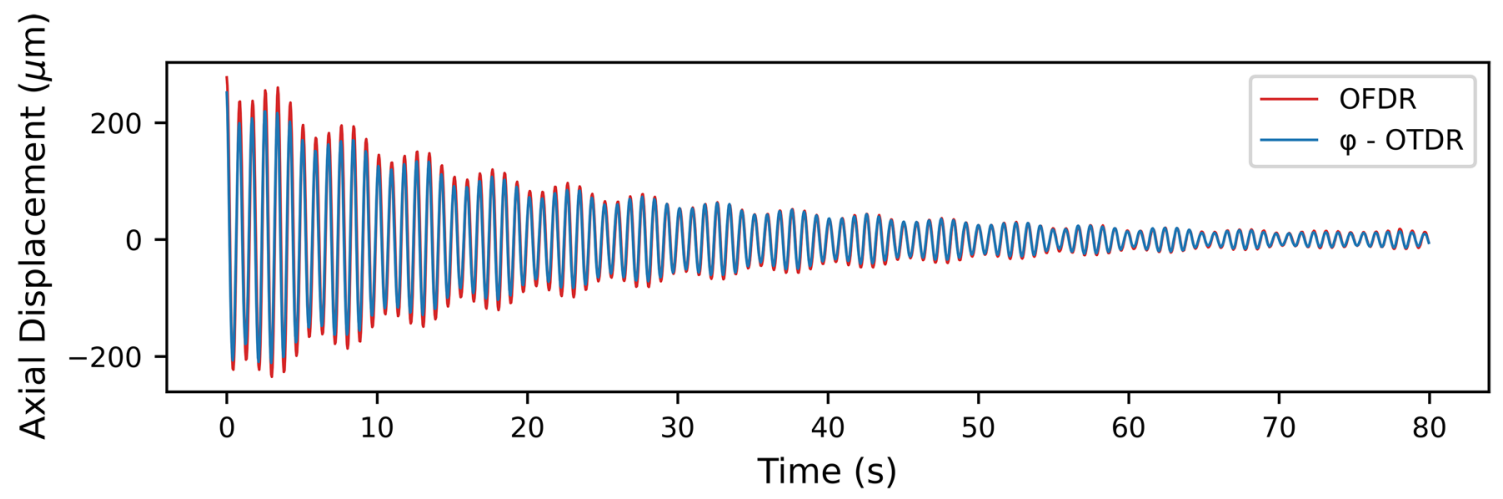

Fig. 17 Displacement time series for the top of the tower in the direction of the sensing fiber during free vibration

$\mathrm{d} U=\frac{\mathrm{d} \varphi \lambda}{4 \pi n \xi}$,

where $\mathrm{d} U$ is the displacement over a single gauge length, $\mathrm{d} \varphi$ is the optical phase shift in radians, $\lambda$ is the operational optical wavelength in vacuum, $n$ is the refractive index of the sensing fiber, and $\xi$ is the photo-elastic scaling factor.

The sensing fiber's total elongation can be determined by using Eq. 4 to calculate the displacement for each gauge length along a sensing fiber and summing. The spatially integrated OFDR measurements and spatially accumulated $\phi$-OTDR measurements at each time can be analyzed as time series data, still sampled at the original $25 \mathrm{~Hz}$. An example of this time series for both OFDR and $\phi$-OTDR is shown in Fig. 17 as the cumulative elongation at the top of the north side of the tower during free vibration. The measurements made from OFDR and $\phi$ -OTDR match incredibly well. The average percent error in the $\phi$-OTDR data, with the OFDR data as the reference point, is $-4.4 \%$. This is sufficient to conclude that $\phi$-OTDR is effective at measuring strain and therefore displacement in a SHM application; it is comparable to the state-of-the-art OFDR system.

By calculating the time-series shown in Fig. 17 at each readout point for both OFDR and $\phi$-OTDR and taking their envelope, Fig. 18 is produced. This figure shows the cumulative elongation of both sensing fibers during $80 \mathrm{~s}$ of the free vibration test. In addition, two spatial profiles at 0 and $40 \mathrm{~s}$ comparing the OFDR and $\phi$-OTDR measurements are shown. This figure shows that the dynamic displacement measurements made by $\phi$-OTDR and OFDR agree at all locations on the sensing fiber. Furthermore, it shows that the correlation between the datasets is not amplitude dependent. Figure 18 also demonstrates the readout resolution difference between the technologies. $\phi$-OTDR is shown as individual blue lines in the 3-D plot and discrete points in the cross sections because measurements have a $1 \mathrm{~m}$ spacing. The OFDR data appears as a solid surface and then solid lines in the 3-D and cross section plots. This is because the OFDR data are spaced $2.6 \mathrm{~mm}$ along the sensing line. Therefore, the individual points cannot be distinguished. Nonetheless, both technologies capture the same behavior and $\phi$ -OTDR is a solution where less dense data are needed and longer sensing ranges are required.

\section{Conclusion}

OFDR and $\phi$-OTDR dynamic, distributed fiber optic sensing technologies were used to monitor a model wind turbine under free and forced vibration conditions. The measurement distance limited but industry-accepted OFDR was used to validate the dynamic strain measurements made with $\phi$-OTDR. $\phi$-OTDR, also known as $\mathrm{DAS}$, is a technology with a very large maximum sensing distance. The system used in this study has a sensing range of $10 \mathrm{~km}$. This presents the opportunity for monitoring many wind turbines with a single fiber optic cable. They were both tested for their ability to identify changes in strain and natural frequency associated with bolt loosening and local material yielding. It was found that $\phi$ -OTDR is capable of quantitatively measuring strain, and in-turn displacement, at the structural frequencies exhibited by wind turbine towers. A thorough comparison of the two technologies proved that $\phi$-OTDR and OFDR measure displacement fields within $5 \%$ of each other. $\phi$ -OTDR was shown to be able to measure localized strain associated with the opening of flange joints and detect small changes in natural frequency caused by structural damage. 


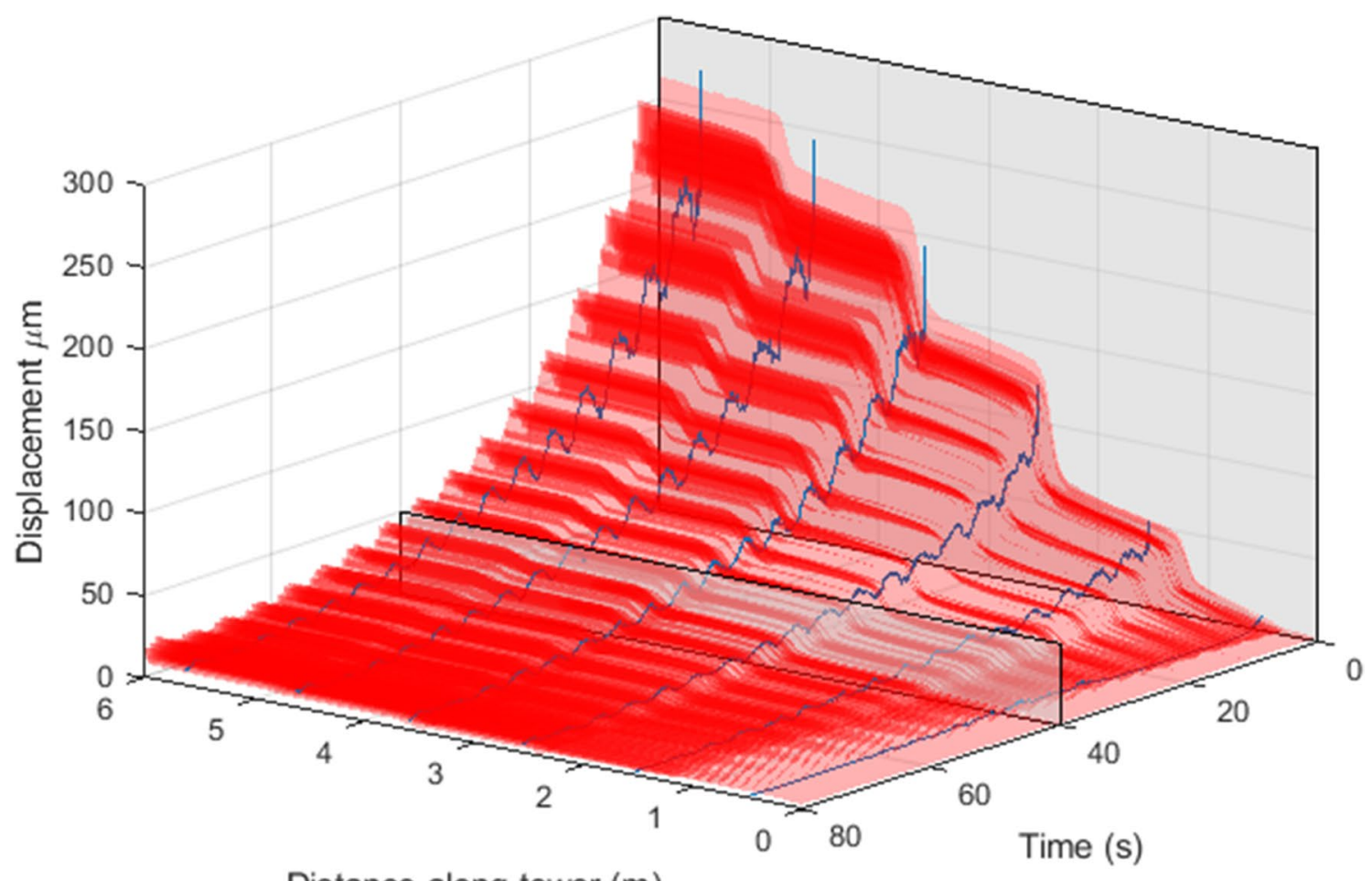

Distance along tower $(\mathrm{m})$

Time (s)
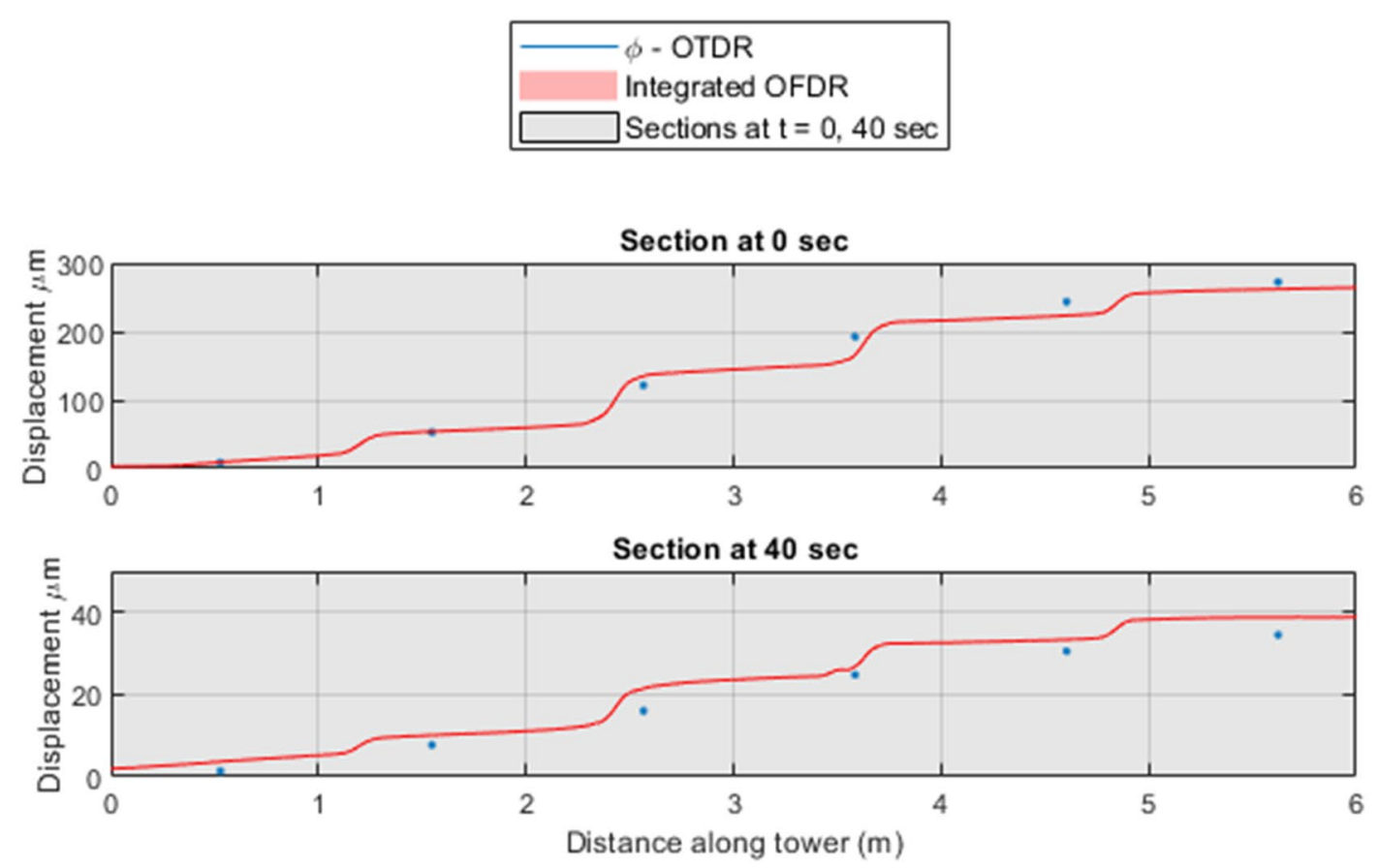

Fig. 18 3-D plot of north axial displacement versus time and location on the tower for both technologies, and 2D plots of displacement vs distance 
Acknowledgements The authors thank Enel Foundation and the Center for Information Technology Research in the Interest of Society and the Banatao Institute for supporting this research. They would also like to thank Enel Green Power's Wind Technology and Innovation Department leads José Alba and Nicola Rossi for their technical advice. Figures 5-14, 16 and 17 were generated using Matplotlib [37].

Funding This work was funded by the Enel Foundation and the Center for Information Technology Research in the Interest of Society and the Banatao Institute (CITRIS).

Availability of data and code Data appearing in this study and the custom code used for its processing are available from the corresponding author upon reasonable request.

Open Access This article is licensed under a Creative Commons Attribution 4.0 International License, which permits use, sharing, adaptation, distribution and reproduction in any medium or format, as long as you give appropriate credit to the original author(s) and the source, provide a link to the Creative Commons licence, and indicate if changes were made. The images or other third party material in this article are included in the article's Creative Commons licence, unless indicated otherwise in a credit line to the material. If material is not included in the article's Creative Commons licence and your intended use is not permitted by statutory regulation or exceeds the permitted use, you will need to obtain permission directly from the copyright holder. To view a copy of this licence, visit http://creativecommons.org/licenses/by/4.0/.

\section{References}

1. Lee J, Zhao F (2019) Global wind report 2019. Global Wind Energy Council, Brussels

2. United Nations (2004) 2001 Energy statistics yearbook. UN, New York

3. United Nations (2021) 2018 Energy statistics yearbook. UN, New York

4. Wiser R, Bolinger M, Lantz E (2019) Assessing wind power operating costs in the United States: results from a survey of wind industry experts. Renew Energy Focus 30:46-57. https://doi.org/ 10.1016/j.ref.2019.05.003

5. Danish Energy Agency and Energinet (2016) Technology data: generation of electricity and district heating. IOP Publishing Danish Energy Agency. https://ens.dk/sites/ens.dk/files/Stati stik/technology_data_catalogue_for_el_and_dh_-_0009.pdf. Accessed 1 Oct 2010

6. SEAFOM (2018) Measuring Sensor Performance Document 02 (SEAFOM MSP-02). IOP Publishing SEAFOM Fiber Optic Monitoring Group. https://seafom.com/mdocs-posts/seafom_msp_ 02-august-2018-pdf. Accessed 15 Dec 2020

7. Weijtjens W, Verbelen T, Capello E, Devriendt C (2017) Vibration based structural health monitoring of the substructures of five offshore wind turbines. Proc Eng 199:2294-2299. https://doi.org/ 10.1016/j.proeng.2017.09.187

8. Kim W, Yi J-H, Kim J-T, Park J-H (2017) Vibration-based structural health assessment of a wind turbine tower using a wind turbine model. Proc Eng 188:333-339. https://doi.org/10.1016/j. proeng.2017.04.492

9. Nguyen C-U, Huynh T-C, Kim J-T (2018) Vibration-based damage detection in wind turbine towers using artificial neural networks. Struct Monit Maint 5(4):507-519
10. Ciang CC, Lee J-R, Bang H-J (2008) Structural health monitoring for a wind turbine system: a review of damage detection methods. Meas Sci Technol. https://doi.org/10.1088/0957-0233/19/12/ 122001

11. Oliveira G, Magalhaes F, Cunha A, Caetano E (2018) Vibrationbased damage detection in a wind turbine using 1 year of data. Struct Control Health Monit. https://doi.org/10.1002/stc.2238

12. Avendano-Valencia LD, Fassois SD (2015) Natural vibration response based damage detection for an operating wind turbine via random coefficient linear parameter varying AR modelling. J Phys Conf Ser 628:24-26. https://doi.org/10.1088/1742-6596/ $628 / 1 / 012073$

13. Xianlong H, Tianli S (2019) A new identification method for bolt looseness in wind turbine towers. Shock Vib. https://doi.org/10. $1155 / 2019 / 6056181$

14. Nguyen CT, Huynh TC, Yi J-H, Kim J-T (2017) Hybrid boltloosening detection in wind turbine tower structures by vibration and impedance responses. Wind StructInt J 24(4):385-403. https://doi.org/10.12989/was.2017.24.4.385

15. Benedetti M, Fontanari V, Zonta D (2011) Structural health monitoring of wind towers: remote damage detection using strain sensors. Smart Mater Struct. https://doi.org/10.1088/0964-1726/20/5/ 055009

16. Bang H-J, Kim H-I, Lee K-S (2012) Measurement of strain and bending deflection of a wind turbine tower using arrayed FBG sensors. Int J Precis Eng Manuf 13:2121-2126. https://doi.org/ 10.1007/s12541-012-0281-2

17. Moyo P, Brownjohn J, Suresh R, Tjin S (2005) Development of fiber bragg grating sensors for monitoring civil infrastructure. Eng Struct 27(12):1828-1834. https://doi.org/10.1016/j.engst ruct.2005.04.023

18. Soga K, Luo L (2018) Distributed fiber optics sensors for civil engineering infrastructure sensing. J Struct Integr Maint 3:1-21. https://doi.org/10.1080/24705314.2018.1426138

19. Masoudi A, Newson TP (2016) Contributed review: distributed optical fibre dynamic strain sensing. Rev Sci Instrum 87:011501. https://doi.org/10.1063/1.4939482

20. Glišic B, Inaudi D (2007) Fibre optic methods for structural health monitoring. Wiley, Chichester

21. Kechavarzi C, Soga K, de Battista N, Pelecanos L, Elshafie M, Mair RJ (2016) Distributed optical fibre sensing for monitoring geotechnical infrastructure: a practical guide. Westminster, London

22. Di Murro V, Pelecanos L, Soga K, Kechavarzi C, Morton RF, Scibile L, (2019) Long-term deformation monitoring of CERN concrete-lined tunnels using distributed fibre-optic sensing. Geotech Eng J SEAGS \& AGSSEA 50(2). http://seags.ait.asia/journ als/32613-seags-agssea-journal-june-2019/. Accessed 6 Jan 2021

23. Li Z, Soga K, Kechavarzi C (2018) Distributed fibre optic sensing of a deep excavation adjacent to pre-existing tunnels. Geotech Lett. https://doi.org/10.1680/jgele.18.00031

24. Pelecanos L, Soga K, Elshafie M, de Battista N, Kechavarzi C, Gue CY, Ouyang Y, Seo H (2018) Distributed fibre optic sensing of axially loaded bored piles. J Geotech Geoenviron Eng. https:// doi.org/10.1061/(ASCE)GT.1943-5606

25. Liu RM, Babanajad SK, Taylor T, Ansari F (2015) Experimental study on structural defect detection by monitoring distributed dynamic strain. Smart Mater Struct 24(11):115038. https://doi. org/10.1088/0964-1726/24/11/115038

26. Oskoui EA, Taylor T, Ansari F (2021) Reference-free dynamic distributed monitoring of damage IN multispan bridges. J Struct Eng 147(1):04020292. https://doi.org/10.1061/(asce)st.1943$541 \mathrm{x} .0002858$

27. Broth Z, Hoult NA (2020) Dynamic distributed strain sensing to assess reinforced concrete behaviour. Eng Struct 204:110036. https://doi.org/10.1016/j.engstruct.2019.110036 
28. Wheeler LN, Pannese E, Hoult NA, Take WA, Le H (2018) Measurement of distributed dynamic rail strains using a Rayleigh backscatter based fiber optic sensor: lab and field evaluation. Transport Geotech. https://doi.org/10.1016/j.trgeo.2017.10.002

29. Luna Innovations Incorporated (2020) Introducing the ODiSI-B 5.1 for Strain \& Temperature. https://lunainc.com/sites/default/ files/assets/files/data-sheet/LUNA-ODiSI-6000-Data-Sheet.pdf. Accessed 12 Jan 2021

30. Hartog AE (2017) An introduction to distributed optical fiber sensors. CRC Press

31. Hall A, Minto C (2019) Using fibre optic cables to deliver intelligent traffic management in smart cities. In: Proceedings: International Conference on smart infrastructure and construction 2019 (ICSIC). https://doi.org/10.1680/icsic.64669.125

32. Daley TM, Freifeld BM, Ajo-Franklin J, Dou S, Pevzner R, Shulakova V, Lueth S (2013) Field testing of fiber-optic distributed acoustic sensing (DAS) for subsurface seismic monitoring. Lead Edge. https://doi.org/10.1190/tle32060699.1

33. Zuo J, Zhang Y, Xu H, Zhu X, Zhao Z, Wei X, Wang X (2020) Pipeline leak detection technology based on distributed optical fiber acoustic sensing system. IEEE Access 8:30789-30796. https://doi.org/10.1109/access.2020.2973229
34. Samiec, D (2012) Optical metrology: distributed fibre-optic temperature and strain measurement with extremely high spatial resolution. IOP Publishing Photonik International. https://www.lambd aphoto.co.uk/pdfs/LUNA/Article\%20-\%20Distributed\%20fibreoptic $\% 20$ temperature $\% 20$ and $\% 20$ strain $\% 20$ measurement $\% 20$ wit hextremely\%20high\%20spatial\%20resolution.pdf. Accessed 19 Jan 2021

35. Luna Innovations Incorporated (2020) ODiSI 6000: Optical Distributed Sensor Interrogators. IOP Publishing Luna Innovations Incorporated. https://lunainc.com/sites/default/files/assets/files/ data-sheet/LUNA-ODiSI-6000-Data-Sheet.pdf. Accessed 30 Jan 2021

36. Hudson DE (1962) Synchronized vibration generators for dynamic tests of full-scale structures. California Institute of Technology. https://authors.library.caltech.edu/26490/1/Hudson_1962.pdf. Accessed 30 Jan 2021

37. Hunter JD (2007) Matplotlib: A 2D graphics environment. Computing Sci Eng 9(3). https://doi.org/10.5281/zenodo.4649959

Publisher's Note Springer Nature remains neutral with regard to jurisdictional claims in published maps and institutional affiliations. 